\title{
Taxonomy of Handover Activities
}

\author{
Ahmad Salman Khan \\ School of ICT \\ Royal Institute of Technology (KTH) \\ Sweden \\ +46-8-16 2846 \\ askhan@kth.se
}

\author{
Mira Kajko-Mattsson \\ School of ICT \\ Royal Institute of Technology (KTH) \\ Sweden \\ +46-8-16 1670 \\ mekm2@kth.se
}

\begin{abstract}
Handover of software systems is a critical stage in the system lifecycle. Despite this, it is still an under researched area. In this paper, we have developed an initial taxonomy of activities for software handover. Our taxonomy consists of seven process components where each component clusters logically coherent activities. The process components are Management and Administration, Maintenance Environment, Version and Configuration Management, Deployment, Training, Documentation and, Maintainability Management.
\end{abstract}

\section{Categories and Subject Descriptors}

D.2.9 [Management]: Software Process Models

\section{General Terms}

Management

\section{Keywords}

Transition, testing, deployment, training, documentation.

\section{INTRODUCTION}

A process during which one hands over a system from development to maintenance is called handover, alias transition. It is a critical stage in the system lifecycle. Maintenance may be strongly impacted if it is not properly managed. Despite this, the research community has not paid much attention to the handover process. Right now, there is only a handful of publications dealing with a handover process [1], [4], [5], [6]. There are no handover process models whatsoever. Neither are there any guidelines for how to manage and execute the process.

In this paper, we have developed a preliminary version of a taxonomy of handover activities. These activities are based on the descriptions of handover processes in [1], [4], [5], [6]. Our goal is to determine basic handover activities and create a basis for creating a handover process model.

The remainder of this paper is as follows. Section 2 presents the

Permission to make digital or hard copies of all or part of this work for personal or classroom use is granted without fee provided that copies are not made or distributed for profit or commercial advantage and that copies bear this notice and the full citation on the first page. To copy otherwise, or republish, to post on servers or to redistribute to lists, requires prior specific permission and/or a fee.

$S 3 M^{\prime} 10$, June 21, 2010, Limerick, Ireland.

Copyright 2010 ACM 1-58113-000-0/00/0010 ...\$10.00. method taken during this study. Section 3 briefly describes handover and presents the preliminary version of our handover process taxonomy. Finally, Section 4 presents conclusions and suggestions for future work.

\section{Method}

We developed our taxonomy in two steps. These are (1) literature survey and (2) taxonomy design. In the literature survey step, we explored research articles and reports dealing with handover. Due to the fact that not much research has been done about handover, we only found a handful of publications in this area. These are [1], [4], [5], [6]. Hence, our taxonomy is based on only these publications.

In the taxonomy design step, we extracted activities from the above listed publications. We then grouped them together based on their logical relationships and put them into components. All in all, we have arrived at 53 activities, out of which 32 are main activities and 21 are their sub activities.

Since the publications on which we base our taxonomy are almost two decades old, we found some obsolete terminologies. To stay in line with current nomenclature, we substituted obsolete terms with the new ones. For example, technical data library was replaced with system documentation repository [6]. Also, some activities in the existent publications were described on a very abstract level. We put more body into them by providing more detail in their descriptions.

\section{Handover}

This section describes the transition process and taxonomy of activities performed for a successful transition of a system. Section 3.1 briefly presents the transition process and Section 3.2 discusses the taxonomy of transition activities in detail.

\subsection{Transition Process}

Handover or transition is a process of transferring responsibilities for a software system from development to maintenance [4], $[5],[6]$.

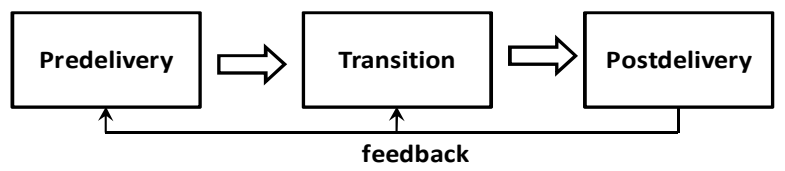

Figure 1. Software handover process [1], [4], [5], [6] 


\begin{tabular}{|c|c|c|c|}
\hline \multicolumn{2}{|c|}{ Management and Administration (MA) } & \multicolumn{2}{|r|}{ Deployment (DP) } \\
\hline \multirow{2}{*}{$\begin{array}{l}\text { MA } 1 . \\
\text { MA 2. } \\
\text { MA 3. } \\
\text { MA 3.1. } \\
\text { MA 3.2. } \\
\text { MA 3.3. } \\
\text { MA 3.4. } \\
\text { MA 3.4.1. } \\
\text { MA 3.4.2. } \\
\text { MA 3.5. } \\
\text { MA 4. }\end{array}$} & \multirow{2}{*}{$\begin{array}{l}\text { Identify maintenance organization. } \\
\text { Establish a transition team. } \\
\text { Create a transition plan. } \\
\text { Determine transition budget. } \\
\text { Create a transition schedule. } \\
\text { Establish transition procedures. } \\
\text { Define transition resource requirements. } \\
\text { Define maintenance manpower } \\
\text { requirements. } \\
\text { Define maintenance facility requirements. } \\
\text { Define other transition elements (not } \\
\text { covered in this study) } \\
\text { Develop management plans. }\end{array}$} & $\begin{array}{l}\text { DP } 1 . \\
\text { DP } 2 . \\
\text { DP } 3 . \\
\text { DP } 3.1 . \\
\text { DP } 3.2 . \\
\text { DP } 3.3 . \\
\text { DP } 3.4 .\end{array}$ & $\begin{array}{l}\text { Develop installation procedures. } \\
\text { Install. } \\
\text { Plan future releases. } \\
\text { Plan updates of future releases. } \\
\text { Determine the distribution structure. } \\
\text { Determine forms of deploying software. } \\
\text { Determine the structure of release notes. }\end{array}$ \\
\hline & & $\begin{array}{l}\text { T1. } \\
\text { T1.1. } \\
\text { T1.2. } \\
\text { T1.3. } \\
\text { T1.4. } \\
\text { T2. } \\
\text { T2.1. }\end{array}$ & \multirow[b]{2}{*}{$\begin{array}{l}\text { Train on system, its structure and operation. } \\
\text { Create/update training material on system, its structure } \\
\text { and operation. } \\
\text { Provide training on system, its structure and operation. } \\
\text { Attend to modification requests. } \\
\text { Conduct white-box testing and debugging. } \\
\text { Train on maintenance processes. } \\
\text { Create/update training material on maintenance } \\
\text { processes. } \\
\text { Provide training on maintenance processes. } \\
\text { Train on system support processes. } \\
\text { Create/update training material on system support } \\
\text { process. } \\
\text { Provide training material on system support process. } \\
\text { Train on new technology to be used within operation } \\
\text { and maintenance. } \\
\text { Create/update training material on new technology. } \\
\text { Provide training material on new technology. } \\
\text { Provide on-site support in critical cases. }\end{array}$} \\
\hline \multirow[t]{2}{*}{$\begin{array}{l}\text { ME } 1 . \\
\text { ME } 2 . \\
\text { ME } 3 . \\
\text { ME } 4 . \\
\text { ME } 5 . \\
\text { ME } 6 . \\
\text { ME } 7 . \\
\text { ME } 8 . \\
\text { ME } 9 . \\
\text { ME } 10 . \\
\text { ME } 11 .\end{array}$} & \multirow[t]{2}{*}{$\begin{array}{l}\text { Maintenance Environment (ME) } \\
\text { Determine hardware/software suite needs. } \\
\text { Install hardware/software suite. } \\
\text { Assess current hardware/software suite, if } \\
\text { any. } \\
\text { Remedy the deficiencies in the } \\
\text { hardware/software suite, if any. } \\
\text { Determine/assess maintenance support suite. } \\
\text { Supplement maintenance support suite with } \\
\text { new tools. } \\
\text { Install support software. } \\
\text { Install software baseline. } \\
\text { Install data. } \\
\text { Transfer modification requests from } \\
\text { development to maintenance. } \\
\text { Place modification requests in a Modification } \\
\text { Request repository. }\end{array}$} & $\begin{array}{l}\text { T1.3. } \\
\text { T1.4. } \\
\text { T2. } \\
\text { T2.1. }\end{array}$ & \\
\hline & & & Documentation (D) \\
\hline \multicolumn{2}{|c|}{ Version and Configuration Management (VC) } & $\begin{array}{l}\text { D2. } \\
\text { D } 3 . \\
\text { D } 4 .\end{array}$ & $\begin{array}{l}\text { Define services to be provided by the system } \\
\text { documentation repository. } \\
\text { Subject system documentation repository to SCM. } \\
\text { Establish standards for documentation development. }\end{array}$ \\
\hline $\begin{array}{l}\text { VC1. } \\
\text { VC2. } \\
\text { vC3. }\end{array}$ & $\begin{array}{l}\text { Establish software configuration baseline. } \\
\text { Put software under software configuration } \\
\text { management. } \\
\text { Place software under version control. }\end{array}$ & $\begin{array}{l}\text { MM } 1 . \\
\text { MM } 2 .\end{array}$ & Maintainability Management (MM) \\
\hline
\end{tabular}

Figure 2. Taxonomy of handover activities [4], [5], [6]

In general, it implies the transfer of a software system and its data, transfer of responsibilities for this system, and transfer of system knowledge and experience.

It is not possible to view software transition as an isolated process. Transition is tightly related to other lifecycle processes such as predelivery development and postdelivery evolution and maintenance. Activities performed during development have great impact on a successful transition and the activities taking place after the transition are strongly impacted by what happens and/or by what does not happen both before and during the transition process. Hence, as shown in Figure 1, software transition should always be considered in the context of Predelivery, Transition and Postdelivery lifecycle stages.

\subsection{Taxonomy}

Our taxonomy consists of seven process components. These are presented in Figure 2. They are Management and Administration, Maintenance Environment, Version and Configuration 
Management, Deployment, Training, Documentation and, Maintainability Management. In this section, we describe these process components and list their respective activities.

\subsubsection{Management and Administration}

The Management and Administration component includes activities required for managing and administrating the transition process [6]. Its first activity suggests identification of a maintenance organization (Activity MA-1). Since a maintenance organization is responsible for postdelivery support, it is important to identify it as early as possible. Early identification helps the maintenance organization to prepare itself for future maintenance. Identifying the maintenance organization, however, is not enough. One must also define a group responsible for the transition (Activity MA-2). According to [5], a separate transition group should be formed within a maintenance organization.

A transition group should create a transition plan (Activity MA-3) identifying the activities to be performed during transition, their timing and order, and roles involved. It is impossible to list all its constituent activities. Hence, we only focus on the most important ones. These are determination of a transition budget (Activity MA3.1), time frames for the transition (Activity MA-3.2), standard operating rules and procedures for managing and coordinating the transition process (Activity MA-3.3), and resources required for the transition process itself (Activity MA-3.4).

As [5] states, some parts in the transition plan overlap with the maintenance plan. These concern determination of the maintenance resources including both manpower and facility requirements (Activity MA-3.4). The manpower requirements define the size of the maintenance team, the roles involved in it and the order of recruiting the roles (Activity MA-3.4.1). It is recommended to hire software configuration management roles first, testers second, and programmers last [5]. The facility requirements (Activity MA-3.4.2) include hardware and software equipment.

Finally, a number of management plans should be developed well before the transition starts (Activity MA-4). These plans include Software Configuration Management Plan (SCMP), Software Quality Program Plan (SQPP), Software Test Plan (STP) and Training Program Plan (TPP).

\subsubsection{Maintenance Environment}

The Maintenance Environment component includes activities required for setting up the maintenance environment covering hardware and software suites and maintenance support suite. It then includes activities for installing the system and its data and for transferring the modification requests [6].

Maintenance team requires hardware and software suites to provide maintenance services. Hardware and software suites encompass a collection of hardware and software systems providing a platform for installing the transitioned system. Maintenance organizations starting from scratch may have to determine their needs for hardware and software suites, and acquire and install them (Activities $M E-1$ and $M E-2$ ). For maintenance organizations that continue with maintaining a certain pool of systems for a particular developer, it may be sufficient that they assess current hardware and software suites and attend to their deficiencies, if any (Activities $M E-3$ and $M E$ 4).

Maintenance team also requires support suites. The suite stands for a pool of software tools required for performing maintenance. This includes compilers and debugging tools. The maintenance support suite must be determined or assessed (Activities ME-5 and $M E-6)$. If it is insufficient or defective, it then must be repaired or supplemented with new tools. Finally, it must be installed (Activity ME-7).

It is only after maintenance support tools have been installed that one may start installing baseline software and data (Activities $M E$ 8 and $M E-9$ ). Baseline software is the version of the transitioned software system. Data, on the other hand, is baseline and operational data.

Many modification requests get reported during development. However, due various reasons, not all of them get resolved before transition. Some of them will have to be resolved in the postdelivery phase by the maintainer instead. For this reason, they must be handed over to the maintainer group (Activity ME-10) who places them in a Modification Request Repository and attends to them during the postdelivery maintenance phase (Activities ME-11).

The modification requests, their number, severity and criticality aid the maintainer in understanding the system and its condition. They create a basis for planning his work and for starting a relation between maintainer and acquirer.

\subsubsection{Version and Configuration Management}

The Version and Configuration component includes activities needed for tracking and controlling changes in the software system. Its prerequisite activity is the establishment of a configuration baseline corresponding to a baseline version of the system (Activity VC-1) [6]. Having the baseline in place, the maintainer takes it over and puts it under configuration management, preferably, as much automated as possible (Activity $V C$-2). By software system, we mean all system parts including code and all levels of system documentation.

During software evolution, many organizations create multiple variants of the same configuration item. Tracking changes requires version management and control. Therefore, the maintainer should place the modified software under version control (Activity VC-3).

\subsubsection{Deployment}

The Deployment component contains three activities required for installing the software system at the acquirer's site. First, one develops installation procedures such as procedures for generating software builds with associated documentation and training materials (Activity DP-1). Second, one installs the system (Activity $D P-2)$. Finally, one plans future releases, by planning future updates, by determining the structure of the software packages, and by determining forms of deploying them and form of deploying release notes (Activity DP-3). [5],[6]

\subsubsection{Training}

Maintainers cannot perform their duties in a satisfactory way and end-users on the acquirer's side cannot properly use the system if 
they do not possess system knowledge. Hence, they should be provided proper training well before taking over their maintenance and end-user responsibilities.

The Training component contains activities for providing training to the stakeholders of the system. The stakeholders involved are mainly acquirer and maintainer. The component includes training on the system and its architecture (Activity T-1) [6]. Since software systems evolve with time, it also includes the development and update of the training material covering both system operation and maintenance (Activities T-2 and T-3) [6]. Maintainer should also be provided with training on new technology to be used in operation and maintenance of the system (Activity T-4). Finally, the maintainer should provide on-site support in critical cases (Activity T-5) [5]. On-site support fulfills both training and support purposes. According to [6], it is the maintenance team who should provide on-site support.

\subsubsection{Documentation}

The Documentation component includes activities for enabling the transition of documentation. Its activities mainly deal with basic procedures for creating a documentation repository and for establishing the services to be provided by it (Activities $D-1, D-2$ ) [5]. Since software systems evolve with time, the documentation should also remain up-to-date. Hence, the repository should be subjected to the same level of configuration management as code (Activity D-3) [6]. Finally, standards for developing documentation should be defined so that all the stakeholders have a common understanding of the structure and terminology used when documenting their systems (Activity $D-4$ ).

\subsubsection{Maintainability Management}

The system maintainability is a quality attribute that has to be considered throughout the whole software lifecycle. Its management is the main ingredient in the predelivery maintenance phase during which maintainers continuously monitor and control maintainability [2]. In the transition phase, maintainers should make final assessment of maintainability to assure that it conforms to the maintainability requirements. The same applies to data maintainability (Activities $M M-1$ and $M M-2$ ).

\section{Final Remarks and Future Work}

In this paper, we have developed a preliminary taxonomy of handover activities. Our goal is to determine basic handover activities and create a platform for creating a handover process model. The taxonomy consists of seven process components covering main groups of logically coherent activities. The wide span of the taxonomy activities indicates that handover is a complex process. However, the real complexity and its industrial relevance can be revealed only when the taxonomy is matched against industrial handover processes. It is evident from [3] that organizations face critical problems during system handover. These problems concern system knowledge, domain knowledge, communication gap between participating parties, documentation, and tracking system changes. Hence, as a next step, we suggest that the taxonomy be evaluated in an industrial context.

\section{REFERENCES}

[1] April, A., Abran, A. 2008. Software Maintenance Management, Evaluation and Continuous Improvement. John Wiley \& Sons, ISBN 978-0470-14707-8.

[2] Khan, A.S., Kajko-Mattsson, M., Tyrberg, T. 2009. Comparing EM3: Predelivery Maintenance Model with its Industrial Correspondence. In Proceedings of IEEE International Conference on Principles of Information Technology and Applications (PITA'09), ISBN: 978-8360810-22-4, IEEE (2009) 573-582.

[3] Khan, A.S., Kajko-Mattsson, M. 2010. Core handover Problems. In Proceedings of Software Maintenance Maturity Model Workshop (S3M'10), in press.

[4] MIL-HDBK-347. 1990. Military Handbook, Mission critical computer resources software support, (1990), handle.dtic.mil/100.2/ADA23575.

[5] Pigoski, T, M. 1997. Practical Software Maintenance. John Wiley \& Sons, ISBN: 0-471-17001-1, (1997), 135-138.

[6] Vollman, T. 1990. Transitioning from development to maintenance. In Proceedings of Software Maintenance conference, (San Diego, CA, USA, 1990) ISBN: 0-81862091, 189-199. 